\title{
A CRIANÇA ABRIGADA: CONSIDERAÇÕES ACERCA DO SENTIDO DA FILIAÇÃO
}

\author{
Stella Maris de Castro Pipinis Parreira \\ José Sterza Justo ${ }^{\#}$
}

\begin{abstract}
RESUMO. O presente artigo discute os sentidos da filiação para crianças abrigadas, vítimas de violência doméstica. O desejo dessas crianças de recuperar a filiação familiar é analisado como busca de um lugar psicossocial. As crianças abrigadas, que sofreram uma ruptura na filiação primeva e história de vida, flutuam entre vinculações efêmeras, sem referências de seu passado e sem pontos fixos e sólidos para seu assentamento no presente que lhes possam servir de guia ou de novas filiações. Tal condição de desfiliação é focalizada como tendência da sociedade contemporânea em afrouxar vinculações, movimentar os ancoradouros psicossociais e produzir desterritorializações, favorecendo uma subjetividade móvel, não identitária, desenlaçada de encaixes e conexões duradouros. Como conclusão, é apontada a continuidade histórica da vitimização da infância realizada pela condição de trânsito e passagem na qual vive, impeditiva de constituições de vínculos duradouros e sólidos que permitam uma suficiente estabilidade e segurança para a prospecção do mundo.
\end{abstract}

Palavras-chave: família crianças, violência doméstica, filiação.

\section{THE SHELTERED CHILD: CONSIDERATIONS ON FAMILY TIES}

\begin{abstract}
The present study discusses the meaning of family bonding for sheltered children, victims of domestic violence. These children's hope of recovering the family ties is analyzed as a search for a psychosocial status. The sheltered children, who suffered a rupture in the primeval filiation and history of life, float among ephemeral bonding, without references of their past and without fixed and solid points for their establishment in the present to serve as a guide or new filiations. Such condition of unfilial behavior is focused as a tendency of the contemporary society in loosening bonding, moving psychosocial status and producing non-stable situations favoring a movable subjectivity where family ties is not a priority. As a conclusion, it is appointed a historical continuity of oppression of the childhood caused by the condition of transitional attachment in their lives, impeding the building of solid and long term ties in order to allow a sufficient stability and support to face life.
\end{abstract}

Key words: children, domestic violence, family ties.

Abrigada desde dezembro de 2002 em uma casa cuja função é proteger o menor de maus-tratos ou violência, uma criança, em um de nossos encontros me diz que precisa de uma folha para escrever alguns nomes. Nesta folha Vinicius ${ }^{2}$, de cinco anos, escreve a seu modo o nome de três amigos que estavam anteriormente abrigados na mesma entidade e haviam sido transferidos para outras unidades, em virtude do fechamento desta instituição. Posteriormente escreve o nome de sua mãe, Juliana, do bebê (seu irmão por parte de mãe) e de seu pai, Juliano. Por fim escreve seu nome: Vinicius S. S. da Silva. Escolhe outra atividade: um livro de histórias. Peço que me conte a história que lê. Vinicius diz que a história é sobre Juliano, seu pai. O sobrenome de Juliano é Soares e o seu agora é Vinicius S. S. Soares. Vinicius conta que Juliano quer ficar com ele, mas ele vai sair do orfanato e voltar para casa. Sua casa é a casa da mãe, Juliana. Vinicius refere que ela é chata, porque o deixou ficar no orfanato. No final do livro há uma foto do personagem, até então denominado Juliano Soares. Vinicius diz que aquele é Juliano de Souza, pai de Vinicius S. S. de Souza.

O que temos aqui é um breve relato de um dos nossos encontros com crianças abrigadas dentro do projeto intitulado "Experimentar-te: as oficinas de recursos expressivos em uma casa abrigo". Desde

\footnotetext{
1 Apoio: CNPq.

* Mestre em Psicologia.

\# Doutor, docente do Programa de Pós-Graduação em Psicologia da Faculdade de Ciências e Letras da Universidade Estadual Paulista/Assis.

2 Os nomes aqui citados são fictícios.
} 
março de 2004 a instituição na qual vínhamos desenvolvendo o trabalho foi desativada por desentendimentos entre a Vara da Infância e a diretoria da Casa Abrigo. As crianças foram transferidas aos poucos, pois dependiam das vagas disponíveis em outras instituições. Vinicius, a criança que restou de nosso grupo de cinco, foi uma das últimas a sair e acompanhou todas as partidas dos amigos mais próximos ou mais distantes. Poderíamos aqui levantar hipóteses e teorias sobre os possíveis sentidos dessas partidas, que são vividas na maioria das vezes como abandono, porque os outros partem, sem muita explicação, para um lugar desconhecido;. mas preferimos levantar outra discussão: os sentidos da filiação.

A história contada por Vinicius nos fala de um pai (Juliano) com sobrenomes diferentes: Soares e Souza. $\mathrm{O}$ nome de seu pai é o mesmo de sua mãe: Juliana. $\mathrm{O}$ seu sobrenome muda ao longo da história: Silva, Soares, Souza. Seria mesmo um pai com sobrenomes diferentes ou seriam dois pais distintos? Seria um pai com nome de mãe? E ele? Seria um Vinicius ou três ou mais, dependendo da quantidade de sobrenomes que conhecesse? A mãe é uma chata, porque o deixa em uma instituição. Por que, se ele próprio diz que tem uma casa? Para onde vai? Para a casa-mãe-chata ou para a casa-instituição, já que para a casa-paiJuliano as possibilidades são pequenas, ele mesmo o sabe.

Estar em situação de abrigado coloca o sujeito em lugar de passagem (Justo, 1997), onde os vínculos se tornam temporários e as relações, instáveis. No caso de nosso pequeno Vinicius, percebemos que, bem cedo, ele se volta para questões sobre sua própria identidade. Filho de quem eu sou? Se sou filho de alguém e tenho casa, por que continuo aqui? E os meus amigos para onde foram? Aqueles que, como eu, sabiam de mim, aqueles com os quais me encontrava na mesma dor, para onde foram? Pessoas desaparecem e fica-se só, perdido, sem lugar. Questões que, convenhamos, são difíceis e muitas vezes levam um adulto a afastá-las de seus pensamentos.

Outro adolescente atendido por nós se referia à dor de ser reconhecido publicamente como abrigado. Ser abrigado é ser alguém sem família, dizia-nos. Significa lidar com as facetas do abandono e com a falta de referenciais. Significa defrontar-se com a ausência de uma filiação, de um lugar próprio onde o sujeito possa reconhecer-se numa história, no tempo e no espaço, podendo visualizar seu passado, identificar sua linhagem e posicionar-se na rede familiar que assegura seu posicionamento psicossocial primário. Significa deparar-se com a ausência da filiação primária, constituída na vivência afetiva, que designe à criança um lugar psicossocial sólido e seguro, um lugar que the assegure a possibilidade do desejo dentro dos parâmetros da lei, conectando-a assim com os outros e com a cultura de maneira geral.

Pellegrino (1983) realiza uma análise do mito e do Complexo de Édipo, elaborado por Freud, para ressaltar o pacto do indivíduo com a lei da cultura. Nesse sentido, é durante o Complexo de Édipo que o sujeito passa pelo processo de separação com a mãe. A proibição do incesto pelo temor à castração o aproxima da identificação com os valores do pai, representante da ordem, o terceiro instituinte da Lei: etapa fundamental que prepara o indivíduo para tornar-se um membro da sociedade.

Conforme acentua ainda esse autor, não é somente o temor à lei que garante a relação autêntica do indivíduo com a lei da cultura, mas também "na medida em que a criança seja amada e respeitada como pessoa na sua peculiaridade" (Pellegrino, 1983).

Aqui nos esbarramos em um outro problema. $\mathrm{O}$ medo e o desamparo estão presentes desde que estas crianças vão para uma instituição. Se vão para uma casa-abrigo é porque alguns de seus direitos básicos à saúde físico-mental não foram respeitados. $\mathrm{Na}$ instituição, o temor e a insegurança também estão presentes. A criança não compreende exatamente porque foi parar ali e tenderá a atribuir esse acontecimento a uma vontade ou decisão arbitrárias de alguém. Algumas vezes, a mãe, o pai ou algum outro familiar é responsabilizado pelo seu asilamento numa instituição, tal como fez Vinícius ao dizer que a mãe era uma chata por tê-lo deixado ali. Outras vezes, a própria criança se responsabiliza pela sua condição, imputando a si, pela via da culpabilização, os motivos de sua transferência para uma casa-abrigo.

É preciso considerar que, subjetivamente, a transferência da criança, pela família, para uma instituição de abrigo será interpretada por ela, subjetivamente, sob forte pressão dos sentimentos de amor e ódio, decorrentes tanto dos vínculos estabelecidos com as figuras parentais como de suas reações diante de sua situação de sofrimento.

Dessa forma, ela tenderá a interpretar os fatos que circundam sua situação de asilamento como decorrentes da vontade das personagens que compõem sua história, e não de uma lei propriamente dita que pudesse transcender o arbítrio pessoal e, inclusive, protegê-la de atos de transgressão. Onde estariam o amor e o respeito pelo indivíduo em sua singularidade que, como afirma Pellegrino (1983), é fundamental para instituir na criança a autêntica acedência às leis da cultura? 
Quando pensamos na instituição do EstadoGrande-Pai, na relação intrafamiliar, temos o ideário de proteção à criança e ao adolescente. Tirá-los de um ambiente onde seus direitos não estão sendo respeitados e onde a criança e/ou adolescente correm sérios perigos em relação à sua integridade física e/ou psíquica pode ser visto como uma interdição legítima do Estado, representado pelas leis da cultura. Mas o que dizer da intervenção que separa crianças de seus vínculos constituídos com outras crianças, funcionários e freqüentadores da instituição, quando essa separação é imposta pelos altos escalões do poder judiciário ou dos dirigentes das instituições de abrigo, em função de desavenças e/ou posicionamentos políticos que cegam o bom senso e tomam a irracionalidade como guia de decisões, aprofundando ainda mais a desfiliação? O que esperar de um EstadoGrande-Pai que separa os vínculos formados sem dar satisfação, sem dizer aos maiores interessados o motivo e para onde vão? O que dizer de um EstadoPai-Autoritário que abusa do poder para atestar sua magnitude e fazer prevalecer a arbitrariedade daqueles que o representam?

Enfim, a criança ou adolescente encaminhado para instituições de guarda ou abrigo inicia e passa a viver aí sua carreira de pária ou expatriado. Perde uma filiação anterior, qualquer que seja, e não receberá outra que possa servir de âncora para seu posicionamento e direcionamento no mundo. A instituição de abrigo já se coloca como um lugar de passagem e, mesmo que a criança permaneça nela por um longo tempo, dificilmente reconhecerá aí sua própria imagem, pelos estigmas que pesam sobre os asilados, tal como expressou aquele adolescente que disse esconder sua condição de abrigado por sentir-se envergonhado.

\section{A DESFILIAÇÃO PSICOSSOCIAL}

Dentro da instituição de abrigo os menores aprendem, com o tempo, a lidar com as regras e normas, com o poder constituído e com toda a "cultura" institucional, desenvolvendo estratégias de sobrevivência. Criam "bons vínculos" naquele ambiente com pessoas internas e externas à instituição. Um vínculo de troca, negociável, que envolve sedução, caridade e piedade.

Calligaris (1994) realiza uma análise do sentimento de "piedade" que se cria em torno de crianças abandonadas. Ele caracteriza o fato como proveniente de uma catarse social que procura reparar coletivamente um dano ou preencher uma carência fundante de uma dada cultura. No caso das instituições de abrigo, a compaixão e o sentimento de piedade são mais visíveis no vínculo estabelecido pelos voluntários e, dentre eles, particularmente pela chamadas "madrinhas adotivas", personagens típicas dessas instituições. $\mathrm{O}$ que estas pessoas estão investindo nessas crianças? Calligaris sugere a própria salvação do ser humano. Cuidar de uma criança abandonada nem sempre está vinculado a um exercício da cidadania, mas, talvez, à necessidade de buscar nela um afeto que lhe restitua algo sentido como perdido e esvaziado: a sua própria filiação.

Sob essa perspectiva, a criança é sempre vista como objeto de satisfação do desejo do outro. Sua família, seu referencial, suas raízes culturais, éticas e étnicas se perdem, abrindo espaço para outros olhares desejosos, diversos e transitórios. A rebeldia contra tudo e contra todos revela a necessidade de um ambiente que a sustente, uma necessidade de ser reconhecida e vista por alguém (Winnicott, 1987).

Calligaris (2000) entende, ainda, a filiação como um ato de fundação que imprime no sujeito o desejo materno e a correlativa interdição paterna, que constituirão as matrizes psicológicas básicas para a conquista de um lugar próprio. O reconhecimento simbólico do lugar de "filho", na estrutura familiar, só é atingido pelo processo de interdição, pela renúncia de um desejo, necessária para a abertura de outros possíveis.

Com o interdito, a criança terá a oportunidade de encontrar o seu lugar na luta constante contra as frustrações e os desígnios da lei. A cada manifestação sua, estará a lei para designar o seu lugar e, conseqüentemente, para possibilitar à criança reafirmar a sua filiação. No caso de Vinicius, observamos a busca do nome do pai, do eixo central de referência, esmaecido pela inexistência da lei vivenciada no contato com o arbítrio e a vontade do outro.

O que dizer sobre Vinicius, que, entre Silva, Souza, Soares, Casa Abrigo, Vara da Infância, pergunta-se sobre sua filiação?

Em uma perspectiva mais ampla, a falta de filiação aponta para a representação de um mundo fantástico, como se, num passe de mágica, as coisas pudessem se transformar (Calligaris, 2000). Uma das principais preocupações de uma criança abrigada é reencontrar seus pais ou encontrar uma família que a adote; ou seja, ela se consome em tentativas de restabelecer sua filiação ou estabelecer outra que a coloque em alguma linhagem. Tal como Vinicius se lança à procura de um nome de família, as crianças asiladas criam histórias e sonham com o reencontro dos pais ou com sua ida para alguma boa família ou para o convívio com alguma alma generosa que as retire dali. 
No caso de crianças pequenas ou aquelas que já estão há bastante tempo na instituição, é muito intenso e angustiante o drama pelo conhecimento de sua gênese, a batalha pelo saber sobre seu passado, sua história, e sobre seus pais.

Como é sabido desde Freud (1905/1972), o enigma do nascimento assola a criança na fase fálica, fazendo-a lançar-se com afinco no desvendamento de sua origem. Mesmo em crianças mais velhas, é comum aparecerem suspeitas sobre a verdadeira filiação. O fantasma da adoção ronda inevitavelmente a cabeça da criança, gerando muita angústia e sofrimento, podendo persistir por um bom tempo.

Para a criança asilada esse enigma tem menor chance de chegar a um desvendamento satisfatório. Ele é vivido tragicamente, potencializado ou duplicado pela real situação de desconhecimento de sua origem e de sua história.

O saber sobre a origem permite ao sujeito, dentre outras coisas, o acesso a um elemento essencial de sua fundação: o desejo dos progenitores que o trouxeram ao mundo. É comum os pais contarem aos filhos o que significou para eles o nascimento de cada um, as circunstâncias nas quais ocorreu, as expectativas e tantas outras coisas que fascinam os pequenos. Tal historiação é necessária para que a criança possa saber dos desejos que pesam sobre si e dos legados que herdou de seus antepassados, tanto os legados que representam riquezas como aqueles que são tidos como fardos ou dívidas.

Tal como enfatiza Arendt (1972), comentando a importância da transmissão dos legados culturais de uma geração para outra, podemos afirmar que a herança psicológica da criança asilada lhe é deixada sem nenhum testamento, ou seja, ela não sabe dos desejos ou maldições que pesam sobre ela, que inauguraram sua vida e que a acompanham até hoje; assim como não sabe dos motivos e sentidos que a trouxeram ao mundo, pela via dos seus progenitores, também não sabe das intenções de juízes, voluntários, profissionais e demais pessoas que cuidam dela. Vive um eclipse total de sua vida, não há qualquer testamento, qualquer palavra ou história que lhe indique o lugar que foi reservado no mundo dos homens, mediante uma filiação.

\section{INFÂNCIA E DESFILIAÇÃO NA CONTEMPORANEIDADE}

É preciso compreender a questão da filiação familiar da criança dentro do quadro das transformações sociais que ocorrem no panorama da atualidade. Castell (1998) coloca em evidência como uma das principais características da sociedade exatamente o processo de desfiliação. Segundo ele, a economia e as relações sociais na atualidade expõem o sujeito à possibilidade de desligamentos de conexões estabelecidas com o trabalho, instituições, serviços e demais elos da rede de existência social. Assim podem ser entendidos o desemprego, o abrandamento dos vínculos trabalhistas e a desmontagem das políticas de proteção e seguridade social, e até mesmo o enfraquecimento dos laços familiares.

As considerações de Deleuze (1998) sobre as sociedades de controle também são cruciais para a compreensão das territorializações da infância na contemporaneidade. Basicamente esse autor destaca que a sociedade atual substitui os espaços fechados, típicos da sociedade disciplinar, pelos espaços abertos e, com isso, abandona as estratégias de confinamento, colocando em seu lugar controles modulares capazes de acompanhar o sujeito em suas movimentações. A sociedade hoje não precisa mais aprisionar ou confinar, sendo-lhe mais útil e funcional um sujeito ativo, flexível, pluralista, desterritorializado, circulante e capaz de incrementar a velocidade da produção e do consumo (Justo, 2001).

Nessa mesma direção, Bauman, (1998) lança uma tese bastante instigante e esclarecedora. Segundo ele, a sociedade, que até então impunha pesadas renúncias de prazer em troca de segurança e amparo social, hoje, incentiva a realização máxima de prazer através da instigação ao consumo exacerbado; porém, em contrapartida, retira as proteções coletivas, produzindo com isso a instabilidade, a insegurança e o risco.

Uma análise bastante cuidadosa de toda essa transfiguração da sociedade e do sujeito, ressaltando a noção de risco pessoal e social, pode ser encontrada em Moraes e Nascimento (2002). Fundamentalmente, esses autores assinalam que a produção dos espaços abertos e de um sujeito volátil traz à tona a questão do risco e a necessidade de seu gerenciamento. "Trata-se de riscos sociais decorrentes do aumento do desemprego, das novas exigências do mundo do trabalho e da tendência dominante de se afrouxarem os laços de filiação e solidariedade" (Moraes \& Nascimento, 2002, p. 98).

É dentro desse quadro de referência que buscamos compreender o problema da filiação vivido particularmente pela criança asilada nas atuais instituições de abrigo temporário. Embora as singularidades acompanhem cada caso, essas crianças encontram-se bastante expostas à lógica do afrouxamento dos vínculos psicossocias, da movimentação, da compressão do tempo e do espaço, da volatilidade e de tantos outros dispositivos de 
produção da efemeridade, provisoriedade e da desfiliação.

A desfiliação que as crianças abrigadas vivem no plano afetivo em relação às figuras parentais não pode ser dissociada de outras que afetam adolescentes, adultos e velhos em áreas tão variadas como as do trabalho e da convivência com grupos identitários, por exemplo. No fundo, trata-se de uma desfiliação primária, sobre cujos escombros se remontarão as secundárias.

O caso de Vinicius, dentro das especificidades dos acontecimentos que marcaram sua vivência das relações com os pais e culminaram no seu encaminhamento para uma casa abrigo, expressa uma trajetória específica pelo processo de desfiliação constituído na atualidade. Analogamente, sua busca de um sobrenome possível expressa uma tentativa de reconstituição de uma filiação esmaecida ou de refundação de si mediante um significante paterno, que pode ser um Soares, um Souza ou mesmo um genérico Silva.

É importante destacar que a fragilização das filiações na contemporaneidade, se por um lado abranda os vínculos e as referenciações tradicionais do sujeito, por outro o lança à procura de outras ancoragens possíveis, como forma de resistência à pulverização e fragmentação das suas referências identitárias. Esse fenômeno da busca de alternativas de filiação para além das instituições tradicionais, como a família e a escola, faz surgir grupalizações polimorfas em substituição a filiações tradicionais como aquelas realizadas na família e na escola - por outras produzidas na socialidade que ultrapassa $o$ normativo ou o instituído.

Assim como Vinicius procura um Silva ou outro sobrenome qualquer, também tantos outros desfiliados tentam refazer engates e reconstituir referências identitárias básicas em redutos de socialidade criados à revelia da lei ou dos padrões de grupalização e socialização instituídos. O caso dos andarilhos de estrada, analisados por Justo (2004), pode ser tomado como um exemplo de busca de reconstituição da filiação na socialidade criada nessa forma de nomadismo. Desligado de qualquer linhagem psicossocial que demarque seu lugar no mundo, o andarilho busca, na errância, redefinir sua identidade e sua linhagem dentro de marcos e referenciais móveis e provisórios, passando a se reconhecer como errante.

Outro exemplo típico de constituição de filiações nos espaços de socialidade que escapam das normatizações convencionais é apontado por Cruz (2004) em sua análise das grupalizações produzidas pelos chamados "adolescentes em conflito com a lei”.
Segundo a autora, os grupos que se formam entre esses adolescentes irmanados em torno de estratégias de sobrevivência que constroem nessa condição de vida configuram "lugares de filiação". "Esses lugares de filiação apesar de estremecidos pela loucura, pelo uso das drogas e pelo desemprego, ainda são lugares em que esses sujeitos estão territorializados e, muitas vezes, ainda são porto-seguros" (Cruz, 2004, p. 78).

$\mathrm{O}$ drama de Vinicius, destarte, insere-se nesse quadro geral da contemporaneidade marcado pela fragilização dos vínculos psicossociais e dos mecanismos de filiação que, sob a égide da Lei, designam um lugar próprio para o sujeito.

\section{CONSIDERAÇÕES FINAIS}

A história que Vinicius nos conta reitera a sua dor. Apesar dos avanços alcançados, principalmente a partir do Estatuto da Criança e do Adolescente, deparamo-nos com questões bastante antigas, no entanto, tão atuais. $\mathrm{O}$ exercício do poder pelas instituições determina o destino daqueles que delas dependem e que estão inteiramente em suas mãos. E o destino hoje não é menos funesto.

Tomando em consideração as idéias de Deleuze (1998), Castell (1998) e Bauman (1998) sobre a sociedade contemporânea, pensamos que, se antes as crianças e adolescentes abandonados, retirados ou desertores de suas famílias, eram trancafiados em internatos de regime fechado, hoje são lançados à rua ou enviados de uma instituição a outra, vivendo uma eterna condição de passagem, sem a possibilidade de um assentamento psicossocial que garanta uma base sólida para a prospecção da vida.

Observa-se uma tendência à substituição das instituições tradicionais de internato - os antigos orfanatos - onde havia uma maior fixação da criança, por instituições de "externato" ou de "passagem", onde a criança permanece um breve período ou apenas durante o dia. Observa-se, ainda, a explosão do fenômeno da "criança de rua" e o surgimento de programas de educação e assistência destinados a reduzir danos, mantendo as crianças ou adolescentes na rua mesmo ou, no máximo, tentando retirá-las dali durante alguns períodos do dia ou da noite.

Depois do ECA proliferaram as "casas-abrigo" destinadas a acolher crianças desamparadas ou tuteladas pela justiça, porém, com o claro propósito de servir de abrigo temporário, e não de moradia fixa, como era o caso dos orfanatos. A escola passa a ser exigida mais intensamente como local de abrigo da criança, como demonstram a expansão da pré-escola e o aumento dos dias letivos. A família vai deixando de 
ser a única residência da criança e outras instituições vão compartilhando, cada vez mais, a tarefa de cuidar dos pequenos. Vai se configurando e intensificando uma situação de trânsito ou circulação da criança por diferentes instituições, no dia-a-dia. As crianças de classe média transitam por diferentes instituições, como escolas de música, dança e tantas outras, enquanto as crianças dos bairros pobres ou de favelas também transitam por programas assistenciais vários, públicos ou de organizações não governamentais (ONGs), ou simplesmente vagueiam pelas ruas.

O reconhecimento social da infância que se prestou, inicialmente, na Modernidade, na sociedade disciplinar, para o seu confinamento, adestramento e dominação, permanece com vestes diferentes no capitalismo tardio, típico da cultura contemporânea.

Se antes as queixas se referiam a uma filiação opressiva e castradora, hoje não é apenas Vinicius que se ressente da falta de um nome e de uma filiação. Vivemos um momento de profunda e ampla desfiliação social, na qual os laços e vínculos - sejam os afetivos, os trabalhistas ou os de seguridade e proteção - estão sendo cada vez mais enfraquecidos e rompidos, deixando o sujeito à deriva.

\section{REFERÊNCIAS}

Arendt, H. (1972). Entre o passado e o futuro. São Paulo: Perspectiva.

Bauman, Z. (1998). O mal-estar na pós-modernidade. Rio de Janeiro: Zahar.

Calligaris, C. (1994, Julho 24). O reino encantado chega ao fim: a criança vira paródia dos devaneios adultos na era pósindustrial. Folha de S. Paulo (Caderno Mais).
Calligaris, C. (2000). Hello Brasil! Notas de um psicanalista europeu viajando ao Brasil. São Paulo: Escuta.

Castell, R. (1998). As metamorfoses da questão social. Petrópolis: Vozes.

Cruz, S. P. (2004). Quando a condição de existência condena e estilos de vida se tornam perigosos. Em S. França (Org.), Estratégias de controle social (pp. 69-99). São Paulo: Arte \& Ciência.

Deleuze, G. (1998). Conversações (1972-1990). Rio de Janeiro: Ed 4.

Freud, S. (1972). Três ensaios sobre teoria da sexualidade. Rio de Janeiro: Imago (Originalmente publicado em 1905).

Justo, J. S. (1997). A institucionalização vivida pela criança de orfanato. Em A. Merisse, J. S. Justo, L.C. Rocha \& M. S. Vasconcelos, Lugares da infância: reflexões sobre a história da criança na fábrica, creche e orfanato (pp. 71-92). São Paulo: Arte Ciência.

Justo, J. S. (2001). Criatividade no mundo contemporâneo. Em M. S. Vasconcelos (Org.), Criatividade (pp. 59-78). São Paulo: Ed. Moderna.

Justo, J. S. (2004). Dromoliogia contemporânea: o caso dos andarilhos. Em S. França (Org.), Estratégias de controle social (pp. 101-123). São Paulo: Arte \& Ciência.

Moraes, T. D. \& Nascimento, M. L. (2002). Da norma ao risco: transformações na produção da subjetividade. Psicologia em Estudo, 7(1), 91-92.

Pellegrino, H. (1983,11 set.). Pacto edípico e pacto social (Da gramática do desejo à sem-vergonhice brasílica). Folha de $S$. Paulo (Folhetim)

Winnicott, D. W. (1987). Privação e delinqüência. São Paulo: Martins Fontes.

Recebido em 30/07/2004 Aceito em 30/06/2005

Endereço para correspondência: Stella Maris de Castro Pipinis Parreira, Rua Dr. César, 1300, Santana, CEP 02013-004, São Paulo-SP. E-mail: smpipinis@yahoo.com.br 